\title{
Advances in gastropod immunity from the study of the interaction between the snail Biomphalaria glabrata and its parasites: A review of research progress over the last decade
}

\author{
Coustau C. ${ }^{1}$, Gourbal B. ${ }^{2}$, Duval D. ${ }^{2}$, Yoshino T. P. ${ }^{3}$, Adema C. M. ${ }^{4}$, Mitta Guillaume ${ }^{2,{ }^{*}}$
}

${ }^{1}$ INRA CNRS UNS, Sophia Agrobiotech Inst, Sophia Antipolis, France.

2 Univ Montpellier, IFREMER, CNRS, IHPE UMR 5244,Univ Perpignan Via Domitia, F-66860

Perpignan, France.

${ }^{3}$ Univ Wisconsin, Sch Vet Med, Dept Pathobiol Sci, Madison, WI 53706 USA.

${ }^{4}$ Univ New Mexico, Dept Biol, Ctr Evolutionary \& Theoret Immunol, Albuquerque, NM 87131 USA.

*Corresponding author : Guillaume Mitta, email address : mitta@univ-perp.fr

\begin{abstract}
:
This review summarizes the research progress made over the past decade in the field of gastropod immunity resulting from investigations of the interaction between the snail Biomphalaria glabrata and its trematode parasites. A combination of integrated approaches, including cellular, genetic and comparative molecular and proteomic approaches have revealed novel molecular components involved in mediating Biomphalaria immune responses that provide insights into the nature of host-parasite compatibility and the mechanisms involved in parasite recognition and killing. The current overview emphasizes that the interaction between B. glabrata and its trematode parasites involves a complex molecular crosstalk between numerous antigens, immune receptors, effectors and anti-effector systems that are highly diverse structurally and extremely variable in expression between and within host and parasite populations. Ultimately, integration of these molecular signals will determine the outcome of a specific interaction between a $B$. glabrata individual and its interacting trematodes. Understanding these complex molecular interactions and identifying key factors that may be targeted to impairment of schistosome development in the snail host is crucial to generating new alternative schistosomiasis control strategies.
\end{abstract}




\section{Graphical abstract}

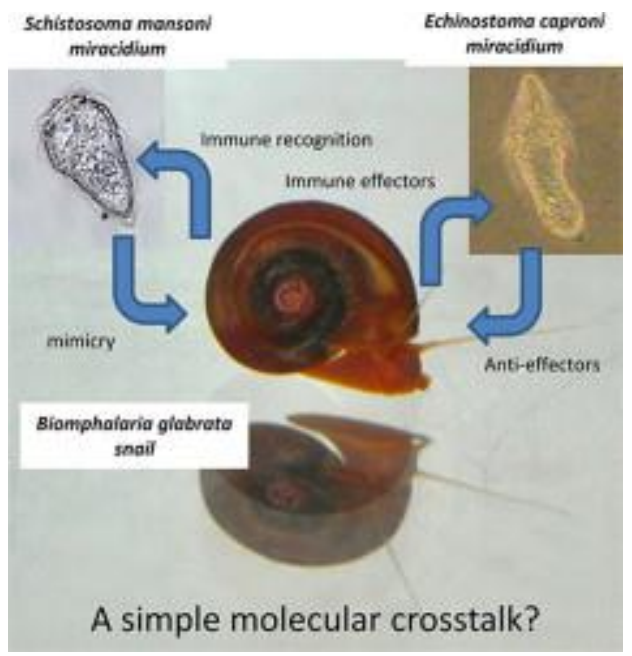

\section{Highlights}

Advances in gastropods immunity in the last decade. We examine the interaction between Biomphalaria and Schistosomes or Echinostomes. The interaction is based on a complex molecular crosstalk. Highly diverse antigens/immune receptors and effectors and anti-effector systems. New alternative control strategies for disrupting schistosomiasis transmission.

Keywords: Biomphalaria glabrata, Schistosoma mansoni, Echinostoma caproni, Immunity, Compatibility 


\section{Introduction:}

Much of our knowledge of gastropod innate immunity has come from investigations of snails that serve as intermediate hosts for the human blood flukes of the genus Schistosoma. Schistosomes are the causative agents of schistosomiasis, one of the most important of the human neglected tropical diseases in the world (WHO, 2014; http://www.who.int/mediacentre/factsheets/fs115/en/ accessed 2015/01/07) Schistosomes infect over 200 million people worldwide causing both acute and chronic, debilitating diseases [1, 2]. There are no effective vaccines against schistosomes, and treatment still relies on a single drug, praziquantel [3]. As praziquantel resistance can be easily selected in the laboratory [4] and some human populations subjected to mass treatment now show evidence of reduced drug susceptibility [5], alternate control strategies are necessary, including strategies for blocking transmission via the snail intermediate host. In this context, understanding the molecular mechanisms of the snail's internal defense system, especially those mediating resistance to schistosomes (and other helminths), could give valuable clues for developing new strategies to disrupt disease transmission.

As pointed out in a recent editorial on the importance of snail research as an integral part of schistosomiasis control schemes [6], a community of investigators has concentrated their research efforts on understanding the mechanisms of snail-trematode compatibility using the model snail species Biomphalaria glabrata whose genome has been sequenced and currently is undergoing assembly and annotation (www.vectorbase.org accessed 2015/01/07). Here we review the major discoveries made over the past decade on innate immunity in B. glabrata from investigations conducted at the cellular, genetic, and molecular levels. Furthermore, gene discovery efforts have resulted in the identification of numerous genes with presumptive immune function, and importantly, have led to the development of molecular tools, such as RNA interference, which has allowed for the functional analysis of some of these genes. Several reviews published in the last five years have focused on digenean - B. glabrata relationships including their immune interactions [6-10]. Here we give a complementary view of B. glabrata immunity by reviewing recent discoveries made over the past decade from non-targeted immune studies as well as from the numerous studies investigating specific questions focusing on the nature of host-parasite compatibility, and the mechanisms underlying resistance and parasite recognition. 


\section{Insights from non-targeted transcriptomic studies}

Although many studies have investigated snail immunity in the context of the B. glabrata/S. mansoni interactions, only a limited number have used non-targeted immune gene discovery methods to provide a survey of potentially immune-related genes. For example, Mitta and collaborators analyzed transcripts expressed by circulating hemocytes (the main effector cells) of Biomphalaria spp. using random sequencing of a hemocyte cDNA library [11]. This allowed identification of several hundred novel transcripts including 31 immune-relevant transcripts corresponding to various functional groups. In addition to usual anticipated candidates such as transcripts coding for enzymes involved in oxidative response or cell adhesion proteins, several unexpected transcripts were identified. In particular, transcripts displaying sequence similarities with the mammalian cytokine MIF (Macrophage Migration Inhibitory Factor) and a PGRP (peptidoglycan recognition protein) were both identified for the first time in any mollusk species.

Following this hemocyte gene discovery study, numerous followup investigations were conducted to identify transcripts differentially expressed during an immune response. B. glabrata snails were exposed to various infectious agents such as trematodes [12-14], bacteria [12,15, 16], or fungi [15], followed by cDNAs analyses using various techniques involving ORESTES or EST sequencing [14], microarrays [12,13] and NGS technologies [15] in order to identify genes responding to these challenges. Altogether, these studies greatly increased the number and diversity of immune-relevant transcripts identified in B. glabrata and helped to establish a substantial repertoire of predicted genes with the potential for serving a functional role in pathogen interactions. Included among these were candidates genes belonging to various functional groups including those coding for pattern recognition proteins (e.g., Fibrinogenrelated proteins (FREPS), PGRPs, macrophage mannose receptor, C-type lectins, galectins), cell adhesion molecules (e.g., dermatopontins, matrilins, integrins), immune regulators (e.g., MIF, Allograft inflammatory factor (AIF), C1q TNF-related protein), cellular defense effectors (e.g., lipopolysaccharide-binding protein/bactericidal permeability-increasing protein (LBP/BPI), lyzozyme), proteases and protease inhibitors (e.g. serpins, serine proteases, trypsin inhibitors, metalloproteinases) or oxidative stress and stress related proteins (e.g. superoxide dismutases (SODs), dual-oxidase, Glutathione S-transferases (GSTs), peroxiredoxins, multidrug resistance 
proteins, soma ferritins, cyclophilins, etc.) as well as candidates involved in regulatory networks and signaling pathways (e.g. Zinc-finger proteins, calmodulins, Thymosin B4) $[11,12,15,16]$.

In addition to providing a growing database of immune-relevant genes, these studies paved the way for complementary targeted and functional studies. For example, the potential existence and involvement of a MIF cytokine in B. glabrata immunity was investigated functionally by RNAi knockdown, in which snail MIF protein was shown to exhibit cellular immune activities similar to those of well known mammalian cytokines [17]. This was followed by other studies that reported the existence of MIF transcripts in other mollusk species including marine species [18] suggesting that this cytokine is a conserved protein among mollusk species. Similarly, several isoforms of PGRPs were identified and characterized in B. glabrata [19]. Three full-length transcripts were shown to originate from a long form PGRP gene (BgPGRP-LA) by alternative splicing and one from a short form PGRP gene (BgPGRP-SA), supporting the existence of the well conserved Toll/Imd immune-signaling pathways in this gastropod snail [19]. Curiously, with the exception of transcripts similar to theromacins [11], the previously mentioned gene discovery studies, including those involving bacterial challenges, did not result in the identification of a diversified arsenal of antimicrobial peptides (AMPs). In contrast, however, cDNAs of antimicrobial proteins such as achacins and LBP/BPIs have been reported in B. glabrata and other molluscs $[11,12,15,16]$. Using a proteomic approach LBP/BPI was identified as a major protein of B. glabrata egg masses [20] and was shown to exhibit a protective its antimicrobial activity [21].

\section{Insights from comparisons of susceptible and resistant snail strains}

The low prevalence of snails with patent schistosome infection usually observed in transmission foci [22, 23] raises the possibility that partial innate resistance could exist in natural snail populations. This hypothesis has been extensively investigated in various laboratories, and genetic studies conducted with different trematode/B. glabrata models. These studies have demonstrated a spectrum of infection susceptibility depending on the host-parasite combination. Results of experimental infection clearly show that susceptible and resistant phenotypes can occur and these are heritable traits that can be selected for under laboratory conditions [24-26]. These genetically-selected susceptible/resistant $B$. glabrata strains have become the model 
organism of choice for investigating the mechanisms underlying resistance and as subjects for comparative molecular studies. The following sections present the work conducted over the past decade on different strains of $B$. glabrata inbred for susceptibility or resistance to two trematode species, Echinostoma caproni and S. mansoni (Figs. 1 and 2).

\section{3.a. Resistance to Echinostoma caproni}

In this model, two strains of $B$. glabrata varying in their susceptibilities to infection by Echinostoma caproni miracidia were selected [27]. While miracidia are able to penetrate both susceptible and resistant snails, the parasite undergoes normal development in susceptible snails, whereas in resistant snails, it is encapsulated in the pericardial region by circulating hemocytes, the main effector cells in snails, resulting in larval death and elimination. Susceptibility/ resistance mechanisms of $B$. glabrata to E. caproni are probably multigenic [27] and rely on both humoral and cellular factors [28]. In vivo comparison of $E$. caproni development in both $B$. glabrata strains revealed that sporocysts were abnormally developed and degenerated regardless of the intensity of the encapsulation response in resistant snails [28]. These results suggested that humoral factors present in snail plasma, in addition to hemocytes, may be actively involved in the molecular processes underlying resistance to E. caproni [28]. As a first approach to identify these factors, a comparative proteomic study was performed on plasma extracts prepared from both strains. Thirteen plasma proteins were differentially represented between strains [29]. These proteins belong to three different classes. The first is a type- 2 secreted cystatin (cysteine protease inhibitors that control activity of cathepsins, ECM-degrading proteases) and was named Bg type2 cystatin. Two other proteins representing a second class were identified as isoforms of secreted calcium-binding proteins of the EF-hand type (designated Bg CaBP 1 and 2) that are known to play a key role in calcium homeostasis. The last two proteins identified were isoforms of an endo $\beta-1,4-m a n n a n a s e$ that are known to randomly cleave within the main chain of galactomannan, glucomannan, galactoglucomannan and mannan [30]. All of these proteins are expressed in the albumen gland and secreted into the hemolymph. They are more abundant in the plasma of susceptible snails and these differences appear correlated with their transcript levels in the albumen gland [29]. Post-infection expression of these five genes is stable in susceptible snails following infection, while they increase significantly in exposed resistant snails [29]. It was proposed that these differences could be linked to a differential regulation of genes in the 
albumen gland between snail strains. In mollusks, the albumen gland is considered as an accessory sexual gland [31] although it has been shown to be involved in the production of defense effector-like agglutinins in planorbid snails [32] or antimicrobial proteins in B. glabrata [20] and several opisthobranch gastropods [33]. The results obtained by Guillou and collaborators [34] supported the view that the albumen gland may play a significant role in immune defense including processes underlying susceptibility/resistance to E. caproni.

Regarding the cellular factors, previous studies showed that excretory-secretory (ES) products from in vitro transformed E. caproni sporocysts inhibited key defence-related functions of susceptible snail hemocytes such as adhesion and phagocytosis [35]. Interestingly, hemocytes from resistant snails remained unaffected by these parasite ES products, suggesting a differential response compared to those of susceptible snails. Comparative approaches were undertaken to identify the molecular basis of this phenotypic difference. Because observed differences appeared to be related to adhesive properties of hemocytes, the expression of genes directly involved in adhesion processes was investigated in both strains [36]. Transcripts of 4 genes were differentially expressed between strains and included transcripts encoding two isoforms of dermatopontin-like proteins (Bg dermatopontin-2 and -3), a matrilin and cadherin [36]. Among these, the dermatopontins seem to be the most promising candidates due their likelihood of being secretory proteins and their share structural features with dermatopontins identified in two other invertebrate species, Suberites domuncula and Limulus polyphemus, which were shown to be involved in adhesive processes [37, 38]. Furthermore, steady-state transcript levels for these two B. glabrata dermatopontin genes were shown to be $i$ ) higher in hemocytes from unexposed resistant snails, and ii) greatly enhanced in resistant snails $48 \mathrm{~h}$ after exposure to the parasite. Interestingly, previous histological studies showed that hemocytic encapsulation reactions to $E$. caproni sporocysts occurred between 48 and 72 hours post exposure [28] in resistant snails, corresponding to the timing of hemocyte dermatopontin gene up-regulation. After this initial targeted transcriptomic approach, a comparative proteomic study was performed using hemocytes of different snail strains [39]. This approach identified 12 proteins that exhibited significant differences in abundance between strains. Among these was a $\mathrm{Bg}$ aldolase, intermediate filament protein, cytidine deaminase, ribosomal protein $\mathrm{P} 1$ and histone $\mathrm{H} 4$ [39]. 
By employing different gene/protein discovery approaches several candidate immune genes have been identified in hemocytes, as well as other tissues (e.g, albumen gland) that may be playing important roles in regulating susceptibility/resistance processes [29, 36, 39]. In order to expand the repertoire of potential immune-related genes differentially expressed in model snail strains, a suppression subtractive hybridization ( $\mathrm{SSH}$ ) method was used to study the two snail strains at the whole body level [40]. Results of this study not only confirmed the differential expression of several genes identified previously, but also new candidate genes belonging to novel functional groups. One of the more promising immune relevant candidates was a gene cluster displaying similarities to the defense factor Aplysianin A, originally purified from the albumen gland of Aplysia kurodai [33]. This factor was highly expressed in resistant B. glabrata when compared to the susceptible strain prompting speculation that its high abundance in resistant snails may be associated with the effective encapsulation response of resistant snails against $E$. caproni.

\section{3.b. Resistance to S. mansoni}

Interactions between $B$. glabrata and $S$. mansoni are characterized by a compatibility polymorphism in which a specific snail strain may be resistant to a specific $S$. mansoni strain while susceptible to another S. mansoni strain [41] (Figure 3). Selection and use of different snail/schistosome combinations were extremely useful to investigate the genetic bases of compatibility as well as the functional mechanisms involved in regulating immune interactions. In the present section we will use the terms "susceptible" and "resistant" for snail strains that allow or disallow, respectively, infection by a specific strain of $S$. mansoni. However, the snail phenotype also is dependent on the schistosome strain used. Studies using snail stocks that are either resistant (13-16-R1 and BS-90 strains) or susceptible (M-line or NMRI strains) to specific $S$. mansoni stocks have clearly demonstrated a strong genetic basis for the susceptibility of $B$. glabrata to $S$. mansoni [25, 42]. Using snail stocks that represent these different susceptibility phenotypes, the genetic loci governing these traits have been assessed by a variety of DNA genotyping tools. These studies have led to the identification of heritable markers related to the parasite-resistance phenotype of adult snails [43]. However, as these sequences are repetitive in the snail genome, further attempts to characterize the associated genes were not successful. A reverse genetic approach using linkage analysis of polymorphic expressed sequence tags (ESTs) expressed simple sequence repeats (eSSRs) - and previously identified bi-allelic microsatellite 
markers, genomic (g)SSRs were used, resulting in the identification of putative genomic locations for resistance gene loci [44]. Similarly other studies have revealed one locus whose allelic variation is associated with snail resistance. This locus corresponds to a linked cluster of redox genes including a gene encoding for a cytosolic copper/zinc SOD (sod1, [45-47]). The current genome assembly and annotation of B. glabrata will significantly facilitate identification of additional genes associated with both resistance and susceptibility in this snail species. Nevertheless, the causality of the previous mentioned associations still remains to be elucidated.

In addition to these genetic approaches, advances have also been made towards the identification of genes associated with snail susceptibility phenotypes by examining differences in gene expression profiles between different snail strains that are either resistant or susceptible to parasite infection. The first studies identifying gene product of immunological relevance was developed by Schneider and collaborators [48] using differential-display reverse-transcription PCR for a comparison of resistant 13-16-R1 and susceptible M-line B. glabrata strains. In this work several partial gene transcripts derived from hemocyte cDNA that displayed similarities to adhesion molecules, kinases, glycosidases and peroxidases were identified, but no further characterization of these candidates were conducted. In subsequent studies, a differential display approach was developed to evaluate gene expression in mantle and brain tissues of the resistant BS90 and susceptible BB02 strains of B. glabrata during experimental exposure to S. mansoni [49]. Several candidate genes were identified and some of them were confirmed to be differentially regulated after challenge. Two of these genes induced in resistant snails following larval exposure displayed similarities with a HSP70 and a myoglobin. Follow-up studies using suppression subtractive hybridization ( $\mathrm{SSH}$ ) with the same snail strains focused on hemocytes and hematopoietic organ to allowed for the identification of transcripts expressed differentially between hemocytes from resistant and susceptible snails [50]. Two of these transcripts, displaying homology with ferritins and serine proteases, were specifically upregulated in BS-90 and $\mathrm{BBO} 2$, respectively. Contrary to the above findings, however, another study using the same SSH methodology, but employing juvenile B. glabrata snails, gave contradictory results: a specific induction of the transcript corresponding to HSP70 was found in susceptible juveniles, but not in the resistant strain. To address the differing results regarding the differential gene expression of HSP70 between snail strains, a quantitative RT-PCR approach was undertaken in which snails were subjected to infection and heat shock. The results confirmed that expression of 
HSP70 is dramatically induced during heat shock as well as after infection in susceptible juvenile snails, but not in the resistant strain [51]. Induction of stress genes after either heat-shock or parasite infection was a major feature distinguishing susceptible juvenile snails from their resistant counterparts. In order to further examine this apparent association between heat stress response and snail susceptibility, the effect of temperature modulation was investigated [52]. Results of this study showed that, if maintained for up to 4 hours at $32^{\circ} \mathrm{C}$ prior to infection, resistant snails became susceptible, suggesting an association or linkage between temperaturesensitivity (heat-shock) and susceptibility to infection in this resistant snail model. Additionally, resistant snails treated with the HSP90-specific inhibitor, geldanamycin (GA) after heat stress, were no longer susceptible to infection, retaining their resistant phenotype. Consistently, susceptible snail phenotypes treated with GA before parasite exposure also remained uninfected. These results suggest a putative role of HSPs and thermal stress in B. glabrata susceptibility to $S$. mansoni infection [52].

Another suppression subtractive hybridization study on whole snail tissues was used to construct forward and reverse cDNA libraries to identify genes involved in the immediate response of juvenile resistant and susceptible snails after early exposure to $S$. mansoni [53]. While no defense-related transcripts were found among juvenile susceptible snail ESTs, several ESTs corresponded to transcripts involved in immune regulation/defense response (C-type lectin, cytidine deaminase, macrophage expressed gene 1, anti-microbial peptide theromacin) were encountered in resistant snails [53]. Using cDNA microarrays a comparison of gene expression in hemocytes from parasite-exposed and control groups of both schistosome-resistant and schistosome-susceptible strains (at 2 hours post exposure) was examined. As previously shown, differences in expression of genes involved in immune/stress response, signal transduction and matrix/adhesion were identified between the two snail strains. These findings supports the hypothesis that schistosome-resistant snails recognize parasites and mount an appropriate defense response, while in schistosome-susceptible snails are unable to defend themselves against infection either because they lack the capacity to recognize and react to the parasite or effector cells (hemocytes) are rendered ineffective by active suppression of the defense response during early in infection [54]. 
In order to gain a better understanding of specific genes involved in regulating snail compatibility, gene-targeted comparative approaches were undertaken on the previous mentioned susceptible and resistant snail strains. For example, since the role of hydrolytic enzymes can be crucial in host-pathogen interactions, a comparative study on proteolytic enzyme activities and transcripts of susceptible and resistant snails was performed [55]. This work revealed differences in cysteine protease activity between both strains and a significant up-regulation of cathepsin B transcripts in resistant (vs. susceptible) snails after parasite exposure. Since hydrogen peroxide $\left(\mathrm{H}_{2} \mathrm{O}_{2}\right)$ was shown to be involved in hemocyte-mediated sporocyst killing [56], the hypothesis that $\mathrm{Cu} / \mathrm{Zn}$ superoxide dismutase ( $\mathrm{SOD}$, a cytosolic enzyme that catalyzes the conversion of superoxide anion to $\mathrm{H}_{2} \mathrm{O}_{2}$ ), could be different between resistant and susceptible snail strains was tested. The amount of steady-state $\mathrm{Cu} / \mathrm{Zn}$ SOD mRNA was constitutively higher in hemocytes from resistant snails, and this correlated directly with a higher $\mathrm{Cu} / \mathrm{Zn}$ SOD enzymatic activity [57] and a higher capacity to produce $\mathrm{H}_{2} \mathrm{O}_{2}$ [58] in resistant snails. A causal relationship between B. glabrata SOD1 expression and susceptibility/resistance to $S$. mansoni was further supported by expression analysis [59] and by genetic-linkage studies [46, 47]. Finally, 52 inbred lines originating from the $B$. glabrata 13-16-R1 snail populations were reared to determine their phenotypes in regard to susceptibility/resistance to $S$. mansoni. These lines displayed differences in numbers of spreading hemocytes with snail lines harboring significantly larger numbers of circulating hemocytes exclusively exhibing resistance to $S$. mansoni, whereas lines characterized by a lower hemocyte number showing variable phenotypes (resistant or susceptible). In the same work, transcript levels in hemocytes were quantified for 18 potential defense-related genes. The different susceptibility/resistance phenotypes correlated with differences in transcript levels for two redox-relevant genes (a predicted phagocyte oxidase component and a peroxiredoxin) and an Allograft Inflammatory Factor (potentially a regulator of leucocyte activation) [60].

\section{Insights from studies into recognition of $S$. mansoni}

During the course of its intramolluscan development, S. mansoni may use different strategies, in a sequential manner, to avoid elimination. Upon penetration into the snail host, miracidia of $S$. mansoni undergo dramatic morphological and physiological changes as they transform into the sporocyst stage [61]. During the first hours of infection, the ciliated epidermal plates of the miracidium detach and epidermal ridges begin to expand for the formation of a new tegument 
[62]. This young post-miracidium parasite is highly vulnerable to host immunity because it is devoid of a protective surface covering until the new tegument is completely formed at about $5 \mathrm{hr}$ post infection. The formation of new tegument included participation of membrane-bound vesicles that discharge their contents into the snail tissues. This apparently helps protect the parasite from host immunity as it prevents snail hemocytes from attachment to the parasite tegument. If a postmiracidium fails to mobilize these membrane-bound vesicles in the formation of tegument, the parasite becomes surrounded by hemocytes and the parasite is eliminated within $24 \mathrm{hr}$ [62]. During these initial first hours of infection, S. mansoni may thus employ an active strategy for avoiding recognition and elimination by the host's immune system [61, 63-65]. It has long been speculated that one of the strategies used by schistosomes to avoid host immune recognition is molecular mimicry $[66,67]$. By expressing host-like antigens or molecules, the parasite is less likely to be recognized as foreign and avoids evoking an immune response [68]. To achieve these different goals, during the different phases of the transformation process, the parasite releases an abundance of diverse proteins that are postulated to serve protective function during formation of the new tegument by the parasite [69]. The parasite-released, so-called Excretory Secretory Products (ESPs) and Larval Transformation Proteins (LTPs) [61, 62, 70] are involved in an arms race between parasite infectivity strategies and host defence mechanisms that ultimately determines the success or failure of host-parasite infections (Figure 3). As a first step to investigate the molecular determinants that play a key role in the cross-talk between snails and schistosomes, the biochemical characterization of ESPs and LTPs of the parasite was undertaken. This led to identification of presence of redox/antioxidant enzymes, glycolytic enzymes, ionbinding proteins including those with putative anti-oxidant Fe-binding activities (ferritins, hemebinding protein) and proteases/protease inhibitors [61, 63]. These findings fit well into a model in which parasite ESP/LTPs protect sporocysts from oxidative damage and other immune effectors of the host. For further understanding of the molecular dialogue between snails and schistosomes, also the characterisation of the molecules directly involved in recognition processes was conducted, not only from the parasite side but also from the perspective of the host.

In $B$. glabrata, a lectin-based system for immune recognition of glycan determinants associated with non-self has been hypothesized to activate immune responses to invading pathogens, including digenetic trematodes $[9,68,71-73]$. In such a system, the sharing of glycan epitopes between invading larvae and elements of the snail's immune system could play a prominent role 
in determining infection success [68, 71, 72]. Investigations of glycan signatures from $B$. glabrata and S. mansoni by Yoshino and collaborators have demonstrated that glycotopes are both abundantly expressed and extremely diverse in structure $[68,71,74,75]$. For example, a 3fucosylated lacdiNAc (LDN) was prominently expressed on the larval surface and amongst glycoproteins released during larval transformation and early sporocyst development [74]. This glycotope was heterogeneously expressed among individual schistosome larvae, particularly miracidia. This implies a possible role for these glycotopes in snail-schistosome compatibility $[68,74,75]$. An independent study investigated antigenic differences between two $S$. mansoni strains, the first being totally compatible (C strain) and the second totally incompatible (IC strain) towards B. glabrata of the same Brazilian strain. Newly penetrated parasites from the IC strain are contacted by host hemocytes within 1 to 2 hours post-infection and entirely encapsulated by 8 to 12 hours post-infection (Figure 3). By contrast, newly-penetrated miracidia of the $\mathrm{C}$ strain were not encapsulated and and developed into primary sporocysts (Sp1) (Figure 3). These observations suggested that constitutive antigenic differences exist between the two schistosome strains. A comparative proteomics approach [76] study revealed that the main difference between these S. mansoni strains corresponded to mucin-like glycoproteins. Mucins are generally known to play key roles in the host-parasite interplay [77-80]. Further study [81] showed that these proteins share several features characteristic of mucins including a $\mathrm{N}$-terminal domain containing a variable number of tandem repeats and a conserved C-terminal domain [81]. The proteins are: (i) only expressed by larval schistosome stages that interact with the snail intermediate host (ii) produced and located in the apical gland of miracidia and sporocysts, (iii), highly glycosylated, and finally (iv) highly polymorphic [81]. Consequently, they were called S. mansoni polymorphic mucins (SmPoMucs). A detailed analysis of their high level of intra- and inter-strain variations showed that SmPoMuc diversification is driven by a complex cascade of mechanisms involving recombinations between members of the $S m$ PoMuc multigene family, post-transcriptional regulation events and post-translational modifications [82]. The consequence of this genetic variability is a remarkably high degree of polymorphism from a limited set of genes making each individual parasite able to express a specific and unique pattern of SmPoMucs.

Taken together, these results suggest that antigenic diversity may explain the differences of compatibility between schistosome and strains of $B$. glabrata snails. For further examination of the putative involvement of SmPoMuc and other glycotopes as targets for recognition by snail 
immune receptors of the snails, an interactome experiment was conducted to characterize snail plasma proteins that interact with the parasite and its products. This approach identified several host lectins and parasite glycoproteins. Among the lectins, FREPs (fibrinogen-related proteins, see below) were identified as well as another B. glabrata lectin that has sequence similarities with a secreted galactose-binding lectin previously described from another gastropod, Helix pomatia [83]. Additional to these snail lectins the interactome also contained several parasitecontributed glycosylated proteins that were identified as SmPoMucs, the $23 \mathrm{kDa}$ integral membrane protein (Sm23 or tetraspanin) and the glycoprotein K5 [84]. Taken together, these results suggest that the recognition process between S. mansoni and B. glabrata is likely multifactorial, involving different immune receptors from the host and different carbohydrate components and/or glycoproteins from the parasite [84].

A complementary co-immunoprecipitation (CoIP) experiment [84] was performed to further study the potential interaction between SmPoMucs and putative immune receptor(s) of the host. Antibodies raised against SmPoMucs were used in antibody pull-down experiments. Analysis showed that SmPoMucs formed molecular complexes B. glabrata FREP lectins, extensively studied plasma immune receptors [85]. The FREPs are perfect candidates for snail molecular determinants of the compatibility polymorphism [72] that determines parasite/snail compatibility on an individual basis. Indeed, FREPs are lectin-like hemolymph proteins that bind and precipitate soluble antigens derived from trematodes [85]. Thorough study has revealed that FREPs are highly polymorphic and that somatic diversification generates unique FREP repertoirtes in individual b. glabrata [86]. A specific review dedicated to these molecules is presented in the present special issue. A third molecular partner was identified in the FREP/SmPoMuc containing complex: a thioester-containing protein from B. glabrata (BgTEP). The presence of $B g$ TEP in the complex was intriguing as molecules of the TEP family play key roles in other invertebrate/pathogen interactions, especially in insects. TEP1 is crucial for phagocytosis of bacteria and killing of Plasmodium parasites in the mosquito Anopheles gambiae. TEP1 from the mosquito is secreted by hemocytes and cleaved in hemolymph into an active form (called mature TEP1 or TEP1-cut, [87]). The C-terminal part of TEP1 binds to bacteria or the ookinete stage of malaria parasites through a thioester bond. The involvement of this complement-like molecule in the antiparasitic defense of mosquitoes was discussed previously [88]. Precursor and phylogenetic analysis of BgTEP suggest that it shares the features with 
invertebrate TEPs that are known to be involved in antiparasitic defense and phagocytosis of micro-organisms [89-92]. In addition, LC-MS/MS analysis of the interactome components led to the identification of peptides that are all located in the C-terminal part of BgTEP, suggesting a thioester-dependent association with the two other partners of the complex. With the indication that BgTEP occurs in activated from in the immune complex, it may well play a role in opsonization processes as previously described for other members of the TEP family. This hypothesis is further supported by the presence of an Alpha2 Macroglobulin receptor binding domain (region 1343-1427) in the C-terminal part of BgTEP precursor [84]. This domain is involved in the interaction with macrophage- and phagocyte-specific receptors [93] and may participate in hemocyte recruitment and capsule formation around incompatible parasites in snail tissues.(Figure 3). Using a combination of affinity chromatography and proteomic analyses, Wu, Yoshino et al. (in preparation) have found that affinity-immobilized sporocyst surface glycoproteins and glycoproteins released during miracidial transformation selectively bind various plasma proteins, notably members of several FREPs subfamilies including Freps 2, 3, 5, 7, and 12, C-type lectins and dermatopontins. These findings support the compatibility polymorphism hypothesis, and suggest that molecular interactions which ultimately lead to host susceptibility or resistance are highly complex and multifactorial.

The interactome study employing B. glabrata plasma and S. mansoni primary sporocyst extracts, also identified a new putative cytolytic protein from B. glabrata named Biomphalysin [84]. Biomphalysin belongs to the $\beta$ pore-forming toxin ( $\beta$-PFT) superfamily that includes virulence factors of amoeba, known to effect lysis by form channels in membranes of target cells [94]. The expression of Biomphalysin is restricted to hemocytes and it is not differentially regulated following parasite challenge. Likely it has a sentinel role in preventing pathogen invasion. Recombinant Biomphalysin had hemolytic activity and was found to bind parasite membranes while it exerts high cytotoxicity toward S. mansoni sporocysts. This functional characterization of Biomphalysin provides for the first time the description of a gastropod immune effector protein involved in S. mansoni killing [94].

In conclusion, highly variable FREPs from B. glabrata form complexes with similarly highly polymorphic and individually variable mucins (the SmPoMucs) from the trematode parasite S. mansoni. Among the different molecules identified in the studies reviewed here, it appears that FREPs and SmPoMucs display the appropriate level of polymorphism to explain at 
least in part the compatibility polymorphism that determines the outcome of infections natural populations of B. glabrata and S. mansoni. These two highly polymorphic systems from the host and the parasite seem to be deployed during the early stages of infection, and this interaction is a likely key component for determining the success or failure of the infection. Several recent studies partially support this supposition. The knock down of FREPs by RNA interference was shown to reduce by 20 to $30 \%$ the individual resistance of B. glabrata to trematode infections [95, 96]. Experiments using SmPoMucs knock-down are currently in progress. In addition, SmPoMuc expression is controlled epigenetically through histone modifications [97] and diversity of expressed SmPoMuc is increased by experimental modification (using Trichostatine A; TSA) of the chromatin status of $S$. mansoni sporocysts treatment [98]. TSA treatment increases (i) the diversity of expressed SmPoMuc and (ii) the compatibility of some parasite strains towards a specific snail strain (Fneich S. and collaborator, personal communication). These results clearly support the view that FREPs (and SmPoMucs) are likely key factors of the compatibility polymorphism. Work is currently ongoing to investigate their role in different natural populations from Africa and South America. When all the results presented in this review are taken together, it seems that also other molecular partners are probably involved. Recognition and immune activation are likely effected through involvement of a large repertoire of interacting molecules. Several host lectins and glycoproteins or glycan signatures of the parasite have been identified. In addition to the above mentioned molecules, B. glabrata galectin (BgGal) with galactoside-binding activity was found to display hemagglutinating activity. BgGal was not detected in cell-free plasma; rather it was immunolocalized in the plasma membrane of snail hemocyte sub-populations. This suggests that $\mathrm{BgGal}$ could serve as a pattern recognition receptor that selectively recognizes and binds hemocytes to pathogens that possess appropriate sugar ligands [99].

\section{Insights from studies of the immune response of $B$. glabrata against trematodes}

A synthesis of all results from the many different investigations of the previous decade aimed at study of anti-trematode responses of B. glabrata is challenging due to the differences in experimental designs. Many biological parameters vary among studies including strains of Biomphalaria (BS90, M line), snail size/age, parasite strain (NMRI, PR-1), miracidial dose used for infection, duration of infection( $2 \mathrm{~h}, 5 \mathrm{~h}$ or $12 \mathrm{~h}$ or more post exposure) and the depth of 
sequencing. There is also the need to discriminate between direct and indirect effects resulting from parasite activities and the inflammation of host tissues due with penetration, intramolluscal development and associated migration events of the parasite. Finally, activation and type of snail defense response depend on the nature of the pathogen [12, 15] or even its genotype [100], indicative of a sophisticated mechanism for antigen recognition. Section 3 presented the molecules involved in recognition. Here, the focus is on the transcriptomic upregulation of the genes involved encompassing genes encoding immune receptors as well as those encoding immune effectors and the genes reflecting cellular activation processes in hemocytes and other tissues that are involved in anti-trematode responses.

\section{5.a. Inducible immune receptors}

In different transcriptomic approaches using microarray, and SSH, FREPs were shown to be expressed at increased abundance after challenge resistant and susceptible snails by $E$. paraensei $[12,13]$ or $S$. mansoni $[12,13,101,102]$. A comparison showed that specific patterns of FREP are evoked depending on the species of parasite used for infection. In addition, the kinetics of induction for different FREPS differs between species. For example, Frep 2 and 4 are highly expressed earlier during E. paraensi challenge in susceptible snails [103] and Frep 3 and 7 later on. Other types of lectins also respond to infection. First, galectins were detected after S. mansoni infection in susceptible snails [12,13] as well as in resistant snails [53]. One of these galectins functions through its binding ability to the tegument of schistosome sporocyst in carbohydratedependent hemocyte adhesion [99]. Single domain C-type lectins represent a third category of lectins that responds to both E. caproni [34] and S. mansoni (susceptible snails, [104]). The Ctype lectin identified by Guillou and co-workers was expressed in the albumen gland [34], and organ with putative role in immunity [29]. Finally, a C1q-like lectin displays an elevated transcription level after challenge of susceptible snails by E. paraensei and S. mansoni [12, 13]. C1q-like proteins may interact with fucosylated determinants that are absent in snail [105] but that predominate on parasite tegument [106-108]. In addition, Castillo and coworkers have demonstrated that the binding activity of some fucose-binding proteins promotes adhesion of snail hemocytes to sporocysts [109]. To conclude this section on lectins, the diversity observed and their transcriptional kinetics in response to different types of infections suggest that they play 
a crucial role in the recognition of trematode antigens leading to the development of an efficient anti-trematode response.

\section{5.b. Inducible immune effectors}

After injury and/or recognition of the parasite, different molecular pathways were activated that may help B. glabrata to develop a response against the challenging infection. All the factors that were identified as participants correspond to three different classes of effectors: (i) proteases/protease inhibitors, (ii) Reactive oxygen species (ROS) and reactive nitrogen species (RNS) and (iii) antimicrobial proteins.

-Proteases and protease inhibitors: After penetration by a parasite, detection by the snail host of miracidia (compatible or not) that attempt to establish yields an inducible systemic transcriptional activity. This reponse may be induced by inflammatory processes that are linked to injury due to mechanical [110] and proteolytic [111] activities of miracidia. In this context, induction of many extracellular components participating in cell/ cell or cell /matrix interactions such as MFAP4 (microfibrillar associated protein), mucin, dermatopontin and matrilin suggests a dynamic remodeling of the extracellular matrix (ECM) at the time of the penetration by the parasite [11, 101]. Expression patterns of , B. glabrata cathepsin, elastase and $\mathrm{Zn}$ metalloproteinase were also modulated [53, 101]. Additionally, host protease inhibitors like cystatin or serine protease inhibitors were upregulated in resistant hemocytes after challenge with either schistosomes [101] or echinostomes [11]. These factors may counteract parasite proteases in order to maintain adhesive properties of hemocytes and/or defense factors onto the parasite surface. This hypothesis was strengthened by the expression of cystatin in hemocytes that aggregated at the site of infection, and hemocytes that participated in encapsulation of E. caproni [34]. Finally, a Schistosoma mansoni venom allergen-like (SmVAL) protein was shown to affect the expression of ECM structuring proteins in B. glabrata [112]. This suggests an enzymatic battle between parasite and snail to control the physicochemical properties of connective tissue to facilitate or prevent migration of the parasite in the snail.

-ROS and RNS: The highly reactive chemical compounds that derive from molecular oxygen and nitrogen (ROS and RNS) are crucial factors of the snail defense against S. mansoni [113]. Conversely, S. mansoni has adapted to this oxidative attack from the snail host by 
developing several antioxidant systems [114]. During transformation of a miracidium to mother sporocyst, the intramolluscan larval parasite expresses an array of antioxidant enzymes like glutathione-S-transferase (GST), $\mathrm{Cu} / \mathrm{Zn}$ superoxide dismutase (SOD), glutathione peroxidase (GPx) and Peroxiredoxins (Prx). [61, 63, 115-117] that are addressed to the newly formed tegumental syncitium for survival of the parasite within the host $[116,118]$. Interestingly, the snail's oxidative burst in response to miracidia penetration seems to be activated by recognition of antigens. Indeed, mannose/galactose/fucose-containing antigens rapidly induce PI3Kdependent production of hydrogen peroxide, the main ROS involved in killing S. mansoni sporocysts $[56,119,120]$. Likely to prevent native cellular damage caused by immune-related production of ROS, B. glabrata engages enzymatic detoxification mechanisms upon parasite infection $[12,13]$.

-Antimicrobial proteins: Snail responses to trematode infection include increased transcription levels for several putative antimicrobial proteins. Prominent among these are genes that belong to the LBP/BPI family. were highly up-regulated especially after echinostome challenge [13, 34]. One particular LBP/BPI protein (i) was expressed in the albumen gland [34], (ii) represented the major protein of B. glabrata egg masses [20] and (iii) displayed antibacterial activity as well as an unexpected activity against oomycetes (aquatic fungi) [21]. Nevertheless, the role of LBP/BPI in anti-trematode defense remains unclear. A second antimicrobial protein was identified as putative Macrophage expressed gene-1 (MPEG1) belonging to the MACPF (membrane-attack complex/perforin) protein superfamily [121]. The corresponding gene was upregulated in hemocytes from resistant snails challenged with $S$. mansoni [53].

5.c. Inducible genes as indicators of cellular activation

To monitor and study an immune response against invaders, it is convenient to focus on immune related genes that are induced after a challenge. Accordingly, many transcriptomic approaches have focused on RNA extracted from whole snails and interpreted snail immunity based on genes transcripts that displayed similarities to immune genes whose function has been elucidated in other biological models. Taking into account the conservation of molecular pathways involved in cellular activation processes, here we focus discussion on cells involved in immune function, the hemocytes, in particular those from resistant snails. First, enhanced intracellular activity (evident 
from expression of genes involved in protein synthesis, membrane trafficking and mitochondrial respiration) was observed in hemocytes from resistant snails after exposure to miracidia [101, 104]. An echinostome infection induced expression of the intermediate filament gene (a cytoskeletal component), this suggests alterations in hemocyte mobility and capability to adhere to the parasite [39]. Similarly, after exposure to S. mansoni, diverse components of the cytoskeleton, such as actin and myosin filaments but also alpha and beta tubulins, were shown to be induced [101]. In addition, regulatory factors of hemocyte motility such as RACK, 14-3-3 proteins and GRK2 are induced after parasite infection [53, 101]. Finally, a cytidine deaminase, putatively involved in RNA editing was induced in resistant snails after challenge [53]. This type of enzyme may also participate in somatic mutation processes to drive diversification of genes that encode B. glabrata immune receptors such as FREPs [86], as well as development of specificity of immune functions in hemocytes [36].

\section{Conclusion:}

Research over the past decade has provided major advances in the field of molluscan immunity, particularly concerning the snail B. glabrata. A diversity of experimental systems comprising different strains of B. glabrata and trematode parasites that display various levels of compatibility has clearly shown that the mechanisms underlying the success or failure of parasite development are multigenic and variable among and within populations. This may reflect the immunological arms race between the host and the parasite that involves recognition mechanisms that include lectin/glycan interactions as well as effector and anti-effector systems like biomphalysins, LBP/BPI, and ROS/ROS scavengers,. It appears that the relative importance of these different factors varies greatly for different populations of host snails and parasites, as was evident for example by the interplay of relative levels of ROS production and ROS scavengers in determining host-parasite compatibility [114]. To date, the contribution of environmental factors as determinant of compatibility between snails and their parasites has probably been underestimated. A recent study indicated an influence of the temperature stress and HSPs on the outcome of $S$. mansoni infection in B. glabrata [52]. Others have shown the influence of previous encounters with other (species or strains of) digenean parasites that may lead to immune priming or "immunization" against future infections.[100]. Finally, epigenetic mechanisms seem to be involved in the expression of some determinants of the compatibility [97] in a manner that 
probably influences the compatibility status between parasite and host partners. A future challenge is to explore the relative importance of these different factors in defining the compatibility status of B. glabrata relative to particular parasites. The assembly and annotation of the B. glabrata genome will facilitate continued development of molecular level studies that are likely to provide novel insights important for addressing this important question. The results from the past decade emphasize that the interaction between $B$. glabrata and its trematode parasites is governed by a complex molecular crosstalk that involves numerous antigens, immune receptors, effectors and anti-effector systems. Some of these molecules are highly diversified and/or are expressed differentially among (populations of) B. glabrata snails and digenean parasites. Therefore, the resolution of a specific interaction between an individual B. glabrata and a particular digenean parasite depends on the integration of numerous individual parameters. Understanding this complex molecular crosstalk and identifying key factors that may be targeted to impair schistosome development in the snail host is crucial to generate avenues for developing new alternative control strategies toward blocking transmission and disruption of the transmission of schistosomiasis.

\section{Acknowledgments}

BG acknowledges support from ANR JCJC INVIMORY number ANR-13-JSV7-0009. TPY acknowledges support from National Institutes of Health (NIH) grant number 2RO1 AI015503. CMA acknowledges support from NIH grant number P20GM103452 from the National Institute of General Medical Sciences (NIGMS). 


\section{References}

1. King CH. Parasites and poverty: the case of schistosomiasis. Acta Tropica. 2010 113:95104. doi: 10.1016/j.actatropica.2009.11.012

2. King CH, Dickman K, Tisch DJ. Reassessment of the cost of chronic helmintic infection: a meta-analysis of disability-related outcomes in endemic schistosomiasis. Lancet. 2005 365:1561-9. doiI: 10.1016/S0140-6736(05)66457-4

3. Doenhoff MJ, Hagan P, Cioli D, Southgate V, Pica-Mattoccia L, Botros S, et al. Praziquantel: its use in control of schistosomiasis in sub-Saharan Africa and current research needs. Parasitology. 2009 136:1825-35. doi: 10.1017/S0031182009000493

4. Fallon PG, Doenhoff MJ. Drug-resistant schistosomiasis: resistance to praziquantel and oxamniquine induced in Schistosoma mansoni in mice is drug specific. American Journal of Tropical Medicine and Hygiene. 1994 51:83-8. no doi

5. Melman SD, Steinauer ML, Cunningham C, Kubatko LS, Mwangi IN, Wynn NB, et al. Reduced susceptibility to praziquantel among naturally occurring Kenyan isolates of Schistosoma mansoni. PLoS Neglected Tropical Diseases. 2009 3:e504. doi: 10.1371/journal.pntd.0000504

6. Adema CM, Bayne CJ, Bridger JM, Knight M, Loker ES, Yoshino TP, et al. Will all scientists working on snails and the diseases they transmit please stand up? PLoS Neglected Tropical Diseases. 2012 6:e1835. doi: 10.1371/journal.pntd.0001835

7. Bayne CJ. Successful parasitism of vector snail Biomphalaria glabrata by the human blood fluke (trematode) Schistosoma mansoni: a 2009 assessment. Molecular and Biochemical Parasitology. 2009 165:8-18. doi: 10.1016/j.molbiopara.2009.01.005

8. Knight M, Arican-Goktas HD, Ittiprasert W, Odoemelam EC, Miller AN, Bridger JM. Schistosomes and snails: a molecular encounter. Front Genet. 2014 5:230. doi: 10.3389/fgene.2014.00230

9. Loker ES. Gastropod immunobiology. Advances in experimental medicine and biology. $2010708: 17-43$.

10. Yoshino TP, Coustau C. Immunobiology of Biomphalaria-trematode interactions. In: Toledo, R, Fried, B (Eds), Biomphalaria Snails and Larval Trematodes. 2011 Springer, New York:pp. 159-89.

11. Mitta G, Galinier R, Tisseyre P, Allienne JF, Girerd-Chambaz Y, Guillou F, et al. Gene discovery and expression analysis of immune-relevant genes from Biomphalaria glabrata hemocytes. Developmental and Comparative Immunology. 2005 29:393-407. doi:10.1016/j.dci.2004.10.002

12. Adema CM, Hanington PC, Lun C-M, Rosenberg GH, Aragon AD, Stout BA, et al. Differential transcriptomic responses of Biomphalaria glabrata (Gastropoda, Mollusca) to bacteria and metazoan parasites, Schistosoma mansoni and Echinostoma paraensei (Digenea, Platyhelminthes). Molecular Immunology. 2010 47:849-60. doi: 10.1016/j.molimm.2009.10.019

13. Hanington PC, Lun CM, Adema CM, Loker ES. Time series analysis of the transcriptional responses of Biomphalaria glabrata throughout the course of intramolluscan development of Schistosoma mansoni and Echinostoma paraensei. International Journal for Parasitology. 2010 40:819-31. doi:10.1016/j.ijpara.2009.12.005

14. Lockyer AE, Spinks JN, Walker AJ, Kane RA, Noble LR, Rollinson D, et al. Biomphalaria glabrata transcriptome: identification of cell-signalling, transcriptional control and immune-related genes from open reading frame expressed sequence tags (ORESTES). Developmental and Comparative Immunology. 2007 31:763-82. doi:10.1016/j.dci.2006.11.004 
15. Deleury E, Dubreuil G, Elangovan N, Wajnberg E, Reichhart JM, Gourbal B, et al. Specific versus non-specific immune responses in an invertebrate species evidenced by a comparative de novo sequencing study. PLoS One. 2012 7:e32512. doi: 10.1371/journal.pone.0032512

16. Hanelt B, Lun CM, Adema CM. Comparative ORESTES-sampling of transcriptomes of immune-challenged Biomphalaria glabrata snails. Journal of invertebrate pathology. 2008 99:192-203. doi: 10.1016/j.jip.2008.06.002

17. Baeza Garcia A, Pierce RJ, Gourbal B, Werkmeister E, Colinet D, Reichhart JM, et al. Involvement of the cytokine MIF in the snail host immune response to the parasite Schistosoma mansoni. PLoS Pathogens. 2010 6:e1001115. doi: 10.1371/journal.ppat.1001115

18. Parisi MG, Toubiana M, Mangano V, Parrinello N, Cammarata M, Roch P. MIF from mussel: coding sequence, phylogeny, polymorphism, 3D model and regulation of expression. Developmental and Comparative Immunology. 2012 36:688-96. doi: 10.1016/j.dci.2011.10.014

19. Zhang SM, Zeng Y, Loker ES. Characterization of immune genes from the schistosome host snail Biomphalaria glabrata that encode peptidoglycan recognition proteins and gramnegative bacteria binding protein. Immunogenetics. 2007 59:883-98. doi: 10.1007/s00251-0070245-3

20. Hathaway JJ, Adema CM, Stout BA, Mobarak CD, Loker ES. Identification of protein components of egg masses indicates parental investment in immunoprotection of offspring by Biomphalaria glabrata (gastropoda, mollusca). Developmental and Comparative Immunology. 2010 34:425-35. doi: 10.1016/j.dci.2009.12.001

21. Baron OL, van West P, Industri B, Ponchet M, Dubreuil G, Gourbal B, et al. Parental transfer of the antimicrobial protein LBP/BPI protects Biomphalaria glabrata eggs against oomycete infections. PLoS Pathogens. 2013 9:e1003792. doi: 10.1371/journal.ppat.1003792

22. Anderson RM, May RM. Prevalence of schistosome infections within molluscan populations: observed patterns and theoretical predictions. Parasitology. 1979 79:63-94. doi:10.1017/S0031182000051982

23. Sire C, Durand P, Pointier JP, Theron A. Genetic diversity and recruitment pattern of Schistosoma mansoni in a Biomphalaria glabrata snail population: a field study using randomamplified polymorphic DNA markers. The Journal of Parasitology. 1999 85:436-41. no doi

24. Davies CM, Webster JP, Woolhous ME. Trade-offs in the evolution of virulence in an indirectly transmitted macroparasite. Proc Biol Sci. 2001 268:251-7. doi: 10.1098/rspb.2000.1367 25. Richards CS, Knight M, Lewis FA. Genetics of Biomphalaria glabrata and its effect on the outcome of Schistosoma mansoni infection. Parasitology Today. 1992 8:171-4. doi:10.1016/0169-4758(92)90015-T

26. Webster JP, Gower CM, Blair L. Do hosts and parasites coevolve? Empirical support from the Schistosoma system. The American Naturalist. 2004164 Suppl 5:S33-51. doi: $10.1086 / 424607$

27. Langand J, Morand S. Heritable non-susceptibility in an allopatric host-parasite system: Biomphalaria glabrata (Mollusca)-Echinostoma caproni (platyhelminth Digenea). The Journal of Parasitology. 1998 84:739-42. doi: 10.2307/3284580

28. Ataev GL, Coustau C. Cellular response to Echinostoma caproni infection in Biomphalaria glabrata strains selected for susceptibility/resistance. Developmental and Comparative Immunology. 1999 23:187-98. doi:10.1016/S0145-305X(99)00023-3

29. Vergote D, Bouchut A, Sautiere PE, Roger E, Galinier R, Rognon A, et al. Characterisation of proteins differentially present in the plasma of Biomphalaria glabrata 
susceptible or resistant to Echinostoma caproni. International Journal for Parasitology. 2005 35:215-24. doi: 10.1016/j.ijpara.2004.11.006

30. Xu B, Hagglund P, Stalbrand H, Janson JC. Endo-beta-1,4-Mannanases from blue mussel, Mytilus edulis: purification, characterization, and mode of action. Journal of Biotechnology. 2002 92:267-77. doi: 10.1016/S0168-1656(01)00367-4

31. Wijdenes J, van Elk R, Joosse J. Effects of two gonadotropic hormones on polysaccharide synthesis in the albumen gland of Lymnaea stagnalis, studied with the organ culture technique. Gen Comp Endocrinol. 1983 51:263-71. doi: 10.1016/0016-6480(83)90080-1

32. Boswell CA, Bayne CJ. Isolation, characterization and functional assessment of a hemagglutinin from the plasma of Biomphalaria glabrata, intermediate host of Schistosoma mansoni. Developmental and Comparative Immunology. 1984 8:559-68. doi: 10.1016/0145305X(84)90088-0

33. Takamatsu N, Shiba T, Muramoto K, Kamiya H. Molecular cloning of the defense factor in the albumen gland of the sea hare Aplysia kurodai. FEBS Letters. 1995 377:373-6. doi: 10.1016/0014-5793(95)01375-X

34. Guillou F, Mitta G, Galinier R, Coustau C. Identification and expression of gene transcripts generated during an anti-parasitic response in Biomphalaria glabrata. Developmental and Comparative Immunology. 2007 31:657-71. doi: 10.1016/j.dci.2006.10.001

35. Humbert E, Coustau C. Refractoriness of host haemocytes to parasite immunosuppressive factors as a putative resistance mechanism in the Biomphalaria glabrata-Echinostoma caproni system. Parasitology. 2001 122:651-60. doi: 10.1017/S003118200100782X

36. Bouchut A, Roger E, Coustau C, Gourbal B, Mitta G. Compatibility in the Biomphalaria glabrata/Echinostoma caproni model: potential involvement of adhesion genes. International Journal for Parasitology. 2006 36:175-84. doi: 10.1016/j.ijpara.2005.09.009

37. Schutze J, Skorokhod A, Muller IM, Muller WE. Molecular evolution of the metazoan extracellular matrix: cloning and expression of structural proteins from the demosponges Suberites domuncula and Geodia cydonium. Journal of Molecular Evolution. 2001 53:402-15. doi: $10.1007 / \mathrm{s} 002390010230$

38. Fujii N, Minetti CA, Nakhasi HL, Chen SW, Barbehenn E, Nunes PH, et al. Isolation, cDNA cloning, and characterization of an $18-\mathrm{kDa}$ hemagglutinin and amebocyte aggregation factor from Limulus polyphemus. Journal of Biological Chemistry. 1992 267:22452-9. no doi

39. Bouchut A, Sautiere PE, Coustau C, Mitta G. Compatibility in the Biomphalaria glabrata/Echinostoma caproni model: Potential involvement of proteins from hemocytes revealed by a proteomic approach. Acta Tropica. 2006 98:234-46. doi: 10.1016/j.actatropica.2006.05.007

40. Bouchut A, Coustau C, Gourbal B, Mitta G. Compatibility in the Biomphalaria glabrata/Echinostoma caproni model: new candidate genes evidenced by a suppressive subtractive hybridization approach. Parasitology. 2007 134:575-88. doi: $10.1017 /$ S0031182006001673

41. Theron A, Coustau C. Are Biomphalaria snails resistant to Schistosoma mansoni? Journal of Helminthology. 2005 79:187-91. doi: 10.1079/JOH2005299

42. Lewis FA, Patterson CN, Knight M, Richards CS. The relationship between Schistosoma mansoni and Biomphalaria glabrata: genetic and molecular approaches. Parasitology. 2001123 Suppl:S169-79. no doi

43. Knight M, Miller AN, Patterson CN, Rowe CG, Michaels G, Carr D, et al. The identification of markers segregating with resistance to Schistosoma mansoni infection in the snail Biomphalaria glabrata. Proceedings of the National Academy of Sciences of the United States of America. 1999 96:1510-5. doi: 10.1073/pnas.96.4.1510 
44. Ittiprasert W, Miller A, Su XZ, Mu J, Bhusudsawang G, Ukoskit K, et al. Identification and characterisation of functional expressed sequence tags-derived simple sequence repeat (eSSR) markers for genetic linkage mapping of Schistosoma mansoni juvenile resistance and susceptibility loci in Biomphalaria glabrata. International Journal for Parasitology. 2013 43:66977. doi: 10.1016/j.ijpara.2013.03.007

45. Blouin MS, Bonner KM, Cooper B, Amarasinghe V, O'Donnell RP, Bayne CJ. Three genes involved in the oxidative burst are closely linked in the genome of the snail, Biomphalaria glabrata. International Journal for Parasitology. 2013 43:51-5. doi: 10.1016/j.ijpara.2012.10.020

46. Bonner KM, Bayne CJ, Larson MK, Blouin MS. Effects of $\mathrm{Cu} / \mathrm{Zn}$ superoxide dismutase (sod1) genotype and genetic background on growth, reproduction and defense in Biomphalaria glabrata. PLoS Neglected Tropical Diseases. 2012 6:e1701. doi: 10.1371/journal.pntd.0001701

47. Goodall CP, Bender RC, Brooks JK, Bayne CJ. Biomphalaria glabrata cytosolic copper/zinc superoxide dismutase (SOD1) gene: association of SOD1 alleles with resistance/susceptibility to Schistosoma mansoni. Molecular and Biochemical Parasitology. 2006 147:207-10. doi: 10.1016/j.molbiopara.2006.02.009

48. Schneider O, Zelck UE. Differential display analysis of hemocytes from schistosomeresistant and schistosome-susceptible intermediate hosts. Parasitology Research. 2001 87:489-91. doi: $10.1007 / \mathrm{s} 004360100394$

49. Lockyer AE, Noble LR, Rollinson D, Jones CS. Schistosoma mansoni: resistant specific infection-induced gene expression in Biomphalaria glabrata identified by fluorescent-based differential display. Experimental Parasitology. 2004 107:97-104. doi: 10.1016/j.exppara.2004.04.004

50. Lockyer AE, Spinks J, Noble LR, Rollinson D, Jones CS. Identification of genes involved in interactions between Biomphalaria glabrata and Schistosoma mansoni by suppression subtractive hybridization. Molecular and Biochemical Parasitology. 2007 151:18-27. doi: 10.1016/j.molbiopara.2006.09.009

51. Ittiprasert W, Nene R, Miller A, Raghavan N, Lewis F, Hodgson J, et al. Schistosoma mansoni infection of juvenile Biomphalaria glabrata induces a differential stress response between resistant and susceptible snails. Experimental Parasitology. 2009 123:203-11. doi: 10.1016/j.exppara.2009.07.015

52. Ittiprasert W, Knight M. Reversing the resistance phenotype of the Biomphalaria glabrata snail host Schistosoma mansoni infection by temperature modulation. PLoS Pathogens. 2012 8:e1002677. doi: 10.1371/journal.ppat.1002677

53. Ittiprasert W, Miller A, Myers J, Nene V, El-Sayed NM, Knight M. Identification of immediate response genes dominantly expressed in juvenile resistant and susceptible Biomphalaria glabrata snails upon exposure to Schistosoma mansoni. Molecular and Biochemical Parasitology. 2010 169:27-39. doi: 10.1016/j.molbiopara.2009.09.009

54. Lockyer AE, Emery AM, Kane RA, Walker AJ, Mayer CD, Mitta G, et al. Early differential gene expression in haemocytes from resistant and susceptible Biomphalaria glabrata strains in response to Schistosoma mansoni. PLoS One. 2013 7:e51102.

55. Myers J, Ittiprasert W, Raghavan N, Miller A, Knight M. Differences in cysteine protease activity in Schistosoma mansoni-resistant and -susceptible Biomphalaria glabrata and characterization of the hepatopancreas cathepsin B Full-length cDNA. The Journal of Parasitology. 2008 94:659-68. doi: 10.1645/GE-1410.1

56. Hahn UK, Bender RC, Bayne CJ. Killing of Schistosoma mansoni sporocysts by hemocytes from resistant Biomphalaria glabrata: role of reactive oxygen species. The Journal of Parasitology; 2001, p. 292-9. doi: 10.1645/0022-3395 
57. Goodall CP, Bender RC, Broderick EJ, Bayne CJ. Constitutive differences in $\mathrm{Cu} / \mathrm{Zn}$ superoxide dismutase mRNA levels and activity in hemocytes of Biomphalaria glabrata (Mollusca) that are either susceptible or resistant to Schistosoma mansoni (Trematoda). Molecular and Biochemical Parasitology. 2004 137:321-8. doi: 10.1016/j.molbiopara.2004.06.011

58. Bender RC, Broderick EJ, Goodall CP, Bayne CJ. Respiratory burst of Biomphalaria glabrata hemocytes: Schistosoma mansoni-resistant snails produce more extracellular $\mathrm{H} 2 \mathrm{O} 2$ than susceptible snails. The Journal of Parasitology. 2005 91:275-9. doi: 10.1645/GE-415R

59. Bender RC, Goodall CP, Blouin MS, Bayne CJ. Variation in expression of Biomphalaria glabrata SOD1: a potential controlling factor in susceptibility/resistance to Schistosoma mansoni. Developmental and Comparative Immunology. 2007 31:874-8. doi: 10.1016/j.dci.2006.12.005

60. Larson MK, Bender RC, Bayne CJ. Resistance of Biomphalaria glabrata 13-16-R1 snails to Schistosoma mansoni PR1 is a function of haemocyte abundance and constitutive levels of specific transcripts in haemocytes. International Journal for Parasitology. 2014 44:343-53. doi: 10.1016/j.ijpara.2013.11.004

61. Wu XJ, Sabat G, Brown JF, Zhang M, Taft A, Peterson N, et al. Proteomic analysis of Schistosoma mansoni proteins released during in vitro miracidium-to-sporocyst transformation. Molecular and Biochemical Parasitology. 2009 164:32-44. doi: 10.1016/j.molbiopara.2008.11.005

62. Pan SC. Schistosoma mansoni: the ultrastructure of larval morphogenesis in Biomphalaria glabrata and of associated host-parasite interactions. Japanese Journal of Medical Science and Biology. 1996 49:129-49. no doi

63. Guillou F, Roger E, Mone Y, Rognon A, Grunau C, Theron A, et al. Excretory-secretory proteome of larval Schistosoma mansoni and Echinostoma caproni, two parasites of Biomphalaria glabrata. Mol Biochem Parasitol. 2007 155:45-56.

64. Sapp KK, Loker ES. Mechanisms underlying digenean-snail specificity: role of miracidial attachment and host plasma factors. The Journal of Parasitology. 2000 86:1012-9. doi: 10.1645/0022-3395(2000)086[1012:MUDSSR]2.0.CO;2

65. Daniel BE, Preston TM, Southgate VR. The in vitro transformation of the miracidium to the mother sporocyst of Schistosoma margrebowiei; changes in the parasite surface and implications for interactions with snail plasma factors. Parasitology. 1992104 Pt 1:41-9. no doi 66. Abu-Shakra M, Buskila D, Shoenfeld Y. Molecular mimicry between host and pathogen: examples from parasites and implication. Immunology Letters. 1999 67:147-52. doi: 10.1016/S0165-2478(99)00004-8

67. Damian RT. Parasite immune evasion and exploitation: reflections and projections. Parasitology. 1997115 Suppl:S169-75. no doi

68. Yoshino TP, Wu XJ, Gonzalez LA, Hokke $\mathrm{CH}$. Circulating Biomphalaria glabrata hemocyte subpopulations possess shared schistosome glycans and receptors capable of binding larval glycoconjugates. Experimental Parasitology. 2013 133:28-36. doi: 10.1016/j.exppara.2012.10.002.

69. Dunn TS, Yoshino TP. Schistosoma mansoni: origin and expression of a tegumental surface antigen on the miracidium and primary sporocyst. Experimental Parasitology. 1988 67:167-81. doi: 10.1016/0014-4894(88)90064-1

70. Lodes MJ, Yoshino TP. Characterization of excretory-secretory proteins synthesized in vitro by Schistosoma mansoni primary sporocysts. The Journal of Parasitology. 1989 75:853-62. no doi 
71. Martins-Souza RL, Pereira CA, Rodrigues L, Araujo ES, Coelho PM, Correa Jr A, et al. Participation of N-acetyl-D-glucosamine carbohydrate moieties in the recognition of Schistosoma mansoni sporocysts by haemocytes of Biomphalaria tenagophila. Memorias do Instituto Oswaldo Cruz. 2011 106:884-91. doi: 10.1590/S0074-02762011000700015

72. Sullivan JT, Belloir JA, Beltran RV, Grivakis A, Ransone KA. Fucoidan stimulates cell division in the amebocyte-producing organ of the schistosome-transmitting snail Biomphalaria glabrata. Journal of invertebrate pathology. 2014 123:13-6. doi: 10.1016/j.jip.2014.09.005

73. Mitta G, Adema CM, Gourbal B, Loker ES, Theron A. Compatibility polymorphism in snail/schistosome interactions: From field to theory to molecular mechanisms. Developmental and Comparative Immunology. 2012 37:1-8. doi: 10.1016/j.dci.2011.09.002

74. Peterson NA, Hokke CH, Deelder AM, Yoshino TP. Glycotope analysis in miracidia and primary sporocysts of Schistosoma mansoni: differential expression during the miracidium-tosporocyst transformation. International Journal for Parasitology. 2009 39:1331-44. doi: 10.1016/j.ijpara.2009.06.002

75. Yoshino TP, Wu XJ, Liu H, Gonzalez LA, Deelder AM, Hokke CH. Glycotope sharing between snail hemolymph and larval schistosomes: larval transformation products alter shared glycan patterns of plasma proteins. PLoS Neglected Tropical Diseases. 2012 6:e1569. doi: 10.1371/journal.pntd.0001569

76. Roger E, Mitta G, Mone Y, Bouchut A, Rognon A, Grunau C, et al. Molecular determinants of compatibility polymorphism in the Biomphalaria glabrata/Schistosoma mansoni model: New candidates identified by a global comparative proteomics approach. Molecular and Biochemical Parasitology. 2008 157:205-16. doi: 10.1016/j.molbiopara.2007.11.003

77. Buscaglia CA, Campo VA, Frasch AC, Di Noia JM. Trypanosoma cruzi surface mucins: host-dependent coat diversity. Nature Reviews Microbiology. 2006 4:229-36. doi: 10.1038/nrmicro1351

78. Hicks SJ, Theodoropoulos G, Carrington SD, Corfield AP. The role of mucins in hostparasite interactions. Part I-protozoan parasites. Parasitology Today. 2000 16:476-81. doi: 10.1016/S0169-4758(00)01773-7

79. Rathore D, Nagarkatti R, Jani D, Chattopadhyay R, de la Vega P, Kumar S, et al. An immunologically cryptic epitope of Plasmodium falciparum circumsporozoite protein facilitates liver cell recognition and induces protective antibodies that block liver cell invasion. Journal of Biological Chemistry. 2005 280:20524-9. doi: 10.1074/jbc.M414254200

80. Theodoropoulos G, Hicks SJ, Corfield AP, Miller BG, Carrington SD. The role of mucins in host-parasite interactions: Part II - helminth parasites. Trends in Parasitology. 2001 17:130-5. doi: 10.1016/S1471-4922(00)01775-X

81. Roger E, Gourbal B, Grunau C, Pierce RJ, Galinier R, Mitta G. Expression analysis of highly polymorphic mucin proteins ( $\mathrm{Sm}$ PoMuc) from the parasite Schistosoma mansoni. Molecular and Biochemical Parasitology. 2008 157:217-27. doi: 10.1016/j.molbiopara.2007.11.015

82. Roger E, Grunau C, Pierce RJ, Hirai H, Gourbal B, Galinier R, et al. Controlled Chaos of Polymorphic Mucins in a Metazoan Parasite (Schistosoma mansoni) Interacting with Its Invertebrate Host (Biomphalaria glabrata). PLoS Neglected Tropical Diseases. 2008 2:e330. doi: 10.1371/journal.pntd.0000330

83. Perez-Sanchez R, Ramajo-Hernandez A, Ramajo-Martin V, Oleaga A. Proteomic analysis of the tegument and excretory-secretory products of adult Schistosoma bovis worms. Proteomics. 20066 Suppl 1:S226-36. doi: 10.1002/pmic.200500420 
84. Mone Y, Gourbal B, Duval D, Du Pasquier L, Kieffer-Jaquinod S, Mitta G. A large repertoire of parasite epitopes matched by a large repertoire of host immune receptors in an invertebrate host/parasite model. PLoS Neglected Tropical Diseases. 2010 4. doi: 10.1371/journal.pntd.0000813

85. Adema CM, Hertel LA, Miller RD, Loker ES. A family of fibrinogen-related proteins that precipitates parasite-derived molecules is produced by an invertebrate after infection. Proceedings of the National Academy of Sciences of the United States of America. 1997 94:8691-6. doi: 10.1073/pnas.94.16.8691

86. Zhang SM, Adema CM, Kepler TB, Loker ES. Diversification of Ig superfamily genes in an invertebrate. Science. 2004 305:251-4. doi: 10.1126/science.1088069

87. Fraiture M, Baxter RH, Steinert S, Chelliah Y, Frolet C, Quispe-Tintaya W, et al. Two mosquito LRR proteins function as complement control factors in the TEP1-mediated killing of Plasmodium. Cell Host Microbe. 2009 5:273-84. doi: 10.1016/j.chom.2009.01.005

88. Volohonsky G, Steinert S, Levashina EA. Focusing on complement in the antiparasitic defense of mosquitoes. Trends in Parasitology. 2010 26:1-3. doi: 10.1016/j.pt.2009.10.003

89. Blandin S, Levashina EA. Thioester-containing proteins and insect immunity. Molecular Immunology. 2004 40:903-8. doi: 10.1016/j.molimm.2003.10.010

90. Blandin SA, Levashina EA. Phagocytosis in mosquito immune responses. Immunology Reviews. 2007 219:8-16. doi: 10.1111/j.1600-065X.2007.00553.x

91. Blandin SA, Marois E, Levashina EA. Antimalarial responses in Anopheles gambiae: from a complement-like protein to a complement-like pathway. Cell Host Microbe. 2008 3:36474. doi: 10.1016/j.chom.2008.05.007

92. Stroschein-Stevenson SL, Foley E, O'Farrell PH, Johnson AD. Identification of Drosophila gene products required for phagocytosis of Candida albicans. PLoS Biology. 2006 4:e4. doi: 10.1371/journal.pbio.0040004

93. van Lookeren Campagne M, Wiesmann C, Brown EJ. Macrophage complement receptors and pathogen clearance. Cellular Microbiology. 2007 9:2095-102. doi: 10.1111/j.14625822.2007.00981.x

94. Galinier R, Portela J, Mone Y, Allienne JF, Henri H, Delbecq S, et al. Biomphalysin, a new beta pore-forming toxin involved in Biomphalaria glabrata immune defense against Schistosoma mansoni. PLoS Pathogens. 2013 9:e1003216. doi: 10.1371/journal.ppat.1003216

95. Hanington PC, Forys MA, Dragoo JW, Zhang SM, Adema CM, Loker ES. Role for a somatically diversified lectin in resistance of an invertebrate to parasite infection. Proceedings of the National Academy of Sciences of the United States of America. 2011 107:21087-92. doi: 10.1073/pnas.1011242107

96. Hanington PC, Forys MA, Loker ES. A somatically diversified defense factor, FREP3, is a determinant of snail resistance to schistosome infection. PLoS Neglected Tropical Diseases. 2012 6:e1591. doi: 10.1371/journal.pntd.0001591

97. Perrin C, Lepesant JM, Roger E, Duval D, Fneich S, Thuillier V, et al. Schistosoma mansoni mucin gene (SmPoMuc) expression: epigenetic control to shape adaptation to a new host. PLoS Pathogens. 2012 9:e1003571. doi: 10.1371/journal.ppat.1003571

98. Cosseau C, Azzi A, Rognon A, Boissier J, Gourbiere S, Roger E, et al. Epigenetic and phenotypic variability in populations of Schistosoma mansoni - a possible kick-off for adaptive host/parasite evolution. Oikos. 2010 119:669-78. doi: 10.1111/j.1600-0706.2009.18040.x

99. Yoshino TP, Dinguirard N, Kunert J, Hokke CH. Molecular and functional characterization of a tandem-repeat galectin from the freshwater snail Biomphalaria glabrata, 
intermediate host of the human blood fluke Schistosoma mansoni. Gene. 2008 411:46-58. doi: 10.1016/j.gene.2008.01.003

100. Portela J, Duval D, Rognon A, Galinier R, Boissier J, Coustau C, et al. Evidence for specific genotype-dependent immune priming in the lophotrochozoan Biomphalaria glabrata snail. J Innate Immun. 2013 5:261-76. doi: 10.1159/000345909

101. Lockyer AE, Emery AM, Kane RA, Walker AJ, Mayer CD, Mitta G, et al. Early differential gene expression in haemocytes from resistant and susceptible Biomphalaria glabrata strains in response to Schistosoma mansoni. PLoS One. 2012 7:e51102. doi: 10.1371/journal.pone.0051102

102. Nowak TS, Woodards AC, Jung Y, Adema CM, Loker ES. Identification of transcripts generated during the response of resistant Biomphalaria glabrata to Schistosoma mansoni infection using suppression subtractive hybridization. The Journal of Parasitology. 2004 90:103440. doi: 10.1645/GE-193R1

103. Hertel LA, Adema CM, Loker ES. Differential expression of FREP genes in two strains of Biomphalaria glabrata following exposure to the digenetic trematodes Schistosoma mansoni and Echinostoma paraensei. Developmental and Comparative Immunology. 2005 29:295-303. doi: 10.1016/j.dci.2004.08.003

104. Raghavan N, Miller AN, Gardner M, FitzGerald PC, Kerlavage AR, Johnston DA, et al. Comparative gene analysis of Biomphalaria glabrata hemocytes pre- and post-exposure to miracidia of Schistosoma mansoni. Molecular and Biochemical Parasitology. 2003 126:181-91. doi: 10.1016/S0166-6851(02)00272-4

105. Zelck UE, Becker W, Bayne CJ. The plasma proteins of Biomphalaria glabrata in the presence and absence of Schistosoma mansoni. Developmental and Comparative Immunology. 1995 19:181-94. doi: 10.1016/0145-305X(95)00012-I

106. Uchikawa R, Loker ES. Echinostoma paraensei and Schistosoma mansoni: adherence of unaltered or modified latex beads to hemocytes of the host snail Biomphalaria glabrata. Experimental Parasitology. 1992 75:223-32. no doi

107. Johnston LA, Yoshino TP. Larval Schistosoma mansoni excretory-secretory glycoproteins (ESPs) bind to hemocytes of Biomphalaria glabrata (Gastropoda) via surface carbohydrate binding receptors. The Journal of Parasitology. 2001 87:786-93. doi: 10.1645/00223395(2001)087[0786:LSMESG]2.0.CO;2

108. Peterson NA, Anderson TK, Wu XJ, Yoshino TP. In silico analysis of the fucosylationassociated genome of the human blood fluke Schistosoma mansoni: cloning and characterization of the enzymes involved in GDP-L-fucose synthesis and Golgi import. Parasites \& vectors. 2013 6:201. doi: 10.1186/1756-3305-6-201.

109. Castillo MG, Wu XJ, Dinguirard N, Nyame AK, Cummings RD, Yoshino TP. Surface membrane proteins of Biomphalaria glabrata embryonic cells bind fucosyl determinants on the tegumental surface of Schistosoma mansoni primary sporocysts. The Journal of Parasitology. 2007 93:832-40. doi: 10.1645/GE-954R.1

110. Blankespoor HD, Van der Schalie H. Attachment and penetration of miracidia observed by scanning electron microscopy. Science. 1976 191:291-3. no doi

111. Yoshino TP, Lodes MJ, Rege AA, Chappell CL. Proteinase activity in miracidia, transformation excretory-secretory products, and primary sporocysts of Schistosoma mansoni. The Journal of Parasitology. 1993 79:23-31. doi: 10.2307/3283272

112. Yoshino TP, Brown M, Wu XJ, Jackson CJ, Ocadiz-Ruiz R, Chalmers IW, et al. Excreted/secreted Schistosoma mansoni venom allergen-like 9 (SmVAL9) modulates host 
extracellular matrix remodelling gene expression. International Journal for Parasitology. 2014 44:551-63. doi: 10.1016/j.ijpara.2014.04.002.

113. Bayne CJ, Hahn UK, Bender RC. Mechanisms of molluscan host resistance and of parasite strategies for survival. Parasitology. 2001123 Suppl:S159-67. no doi

114. Mone Y, Ribou AC, Cosseau C, Duval D, Theron A, Mitta G, et al. An example of molecular co-evolution: reactive oxygen species (ROS) and ROS scavenger levels in Schistosoma mansoni/Biomphalaria glabrata interactions. International Journal for Parasitology. 2011 41:721-30. doi: 10.1016/j.ijpara.2011.01.007

115. Zelck UE, Von Janowsky B. Antioxidant enzymes in intramolluscan Schistosoma mansoni and ROS-induced changes in expression. Parasitology. 2004 128:493-501. doi: 10.1017/S0031182004004895

116. Mourao Mde M, Dinguirard N, Franco GR, Yoshino TP. Role of the endogenous antioxidant system in the protection of Schistosoma mansoni primary sporocysts against exogenous oxidative stress. PLoS Neglected Tropical Diseases. 2009 3:e550. doi: 10.1371/journal.pntd.0000550

117. Vermeire JJ, Taft AS, Hoffmann KF, Fitzpatrick JM, Yoshino TP. Schistosoma mansoni: DNA microarray gene expression profiling during the miracidium-to-mother sporocyst transformation. Molecular and Biochemical Parasitology. 2006 147:39-47. no doi

118. Vermeire JJ, Yoshino TP. Antioxidant gene expression and function in in vitrodeveloping Schistosoma mansoni mother sporocysts: possible role in self-protection. Parasitology. 2007 134:1369-78. no doi

119. Hahn UK, Bender RC, Bayne CJ. Production of reactive oxygen species by hemocytes of Biomphalaria glabrata: carbohydrate-specific stimulation. Developmental and Comparative Immunology. 2000 24:531-41. doi: 10.1016/S0145-305X(00)00017-3

120. Humphries JE, Yoshino TP. Regulation of hydrogen peroxide release in circulating hemocytes of the planorbid snail Biomphalaria glabrata. Developmental and Comparative Immunology. 2008 32:554-62. doi: 10.1016/j.dci.2007.09.001

121. Bathige SD, Umasuthan N, Whang I, Lim BS, Won SH, Lee J. Antibacterial activity and immune responses of a molluscan macrophage expressed gene-1 from disk abalone, Haliotis discus discus. Fish \& Shellfish Immunology. 2014 39:263-72. doi: 10.1016/j.fsi.2014.05.012 


\section{Legends to figure}

\section{Figure 1: Schistosoma mansoni life cycle.}

Schistosoma mansoni has a complex life cycle that involves two hosts. Adult worms mate in the venous system of a vertebrate definitive host. Eggs are expelled with the faeces. If deposited in an aquatic environment, the eggs hatch to release a miracidium that will infect a freshwater snail of the genus Biomphalaria. Within snail tissues, the miracidium transforms into a primary sporocyst that multiplies asexually to produce secondary sporocysts. Secondary sporocysts produce cercariae that emerge from the snail and actively infect a vertebrate definitive host.

\section{Figure 2: Echinostoma caproni life cycle.}

The life cycle of Echinostoma caproni involves three hosts, a vertebrate definitive host (mice are used as experimental host in the laboratory) and invertebrate first and second intermediate hosts (Biomphalaria glabrata may serve in both capacities). Hermaphrodite adult worms reproduce in the gastrointestinal tract of a mouse, unembryonated eggs are released with faeces. If deposited in an aquatic environment, the eggs complete their development, hatch and release miracidia. Miracidia actively penetrate a Biomphalaria glabrata first intermediate host. Within the snail tissues, the miracidia transform to sporocysts that multiply asexually to yield rediae and cercariae. The cercariae leave the snail and actively infect the second intermediate host snail (Biomphalaria glabrata) and encyst to become metacercariae. After ingestion a mouse definitive host, metacercariae excyst in the intestine and develop into adults.

\section{Figure 3: Schistosoma mansoni / Biomphalaria glabrata immunobiological interactions.}

The outcome of infection is dependent on the nature of the host and parasite interaction. The immunobiological interactions of the parasite $(S$. mansoni) towards different strains of $B$. glabrata are either compatible/susceptible (C/S) or incompatible/resistant (I/R).

A. In the $\mathrm{I} / \mathrm{R}$ immunobiological interaction, the parasite was recognized as non-self after penetration, encapsulated and killed by the hemocytes, the snail's circulating immune cells. Note the multi-layer hemocyte capsule surrounding a dead sporocyst at 48 hours after penetration.

B. In the $\mathrm{C} / \mathrm{S}$ imunobiological interaction, the parasite was not recognized and developed normally in snail tissue. The sporocyst is growing in the head-foot of the snail 48 hours after penetration.

The same immune cellular response processes were observed in the interaction between Echinostoma caproni and B. glabrata. 
Figure 1

\section{Figure 1}

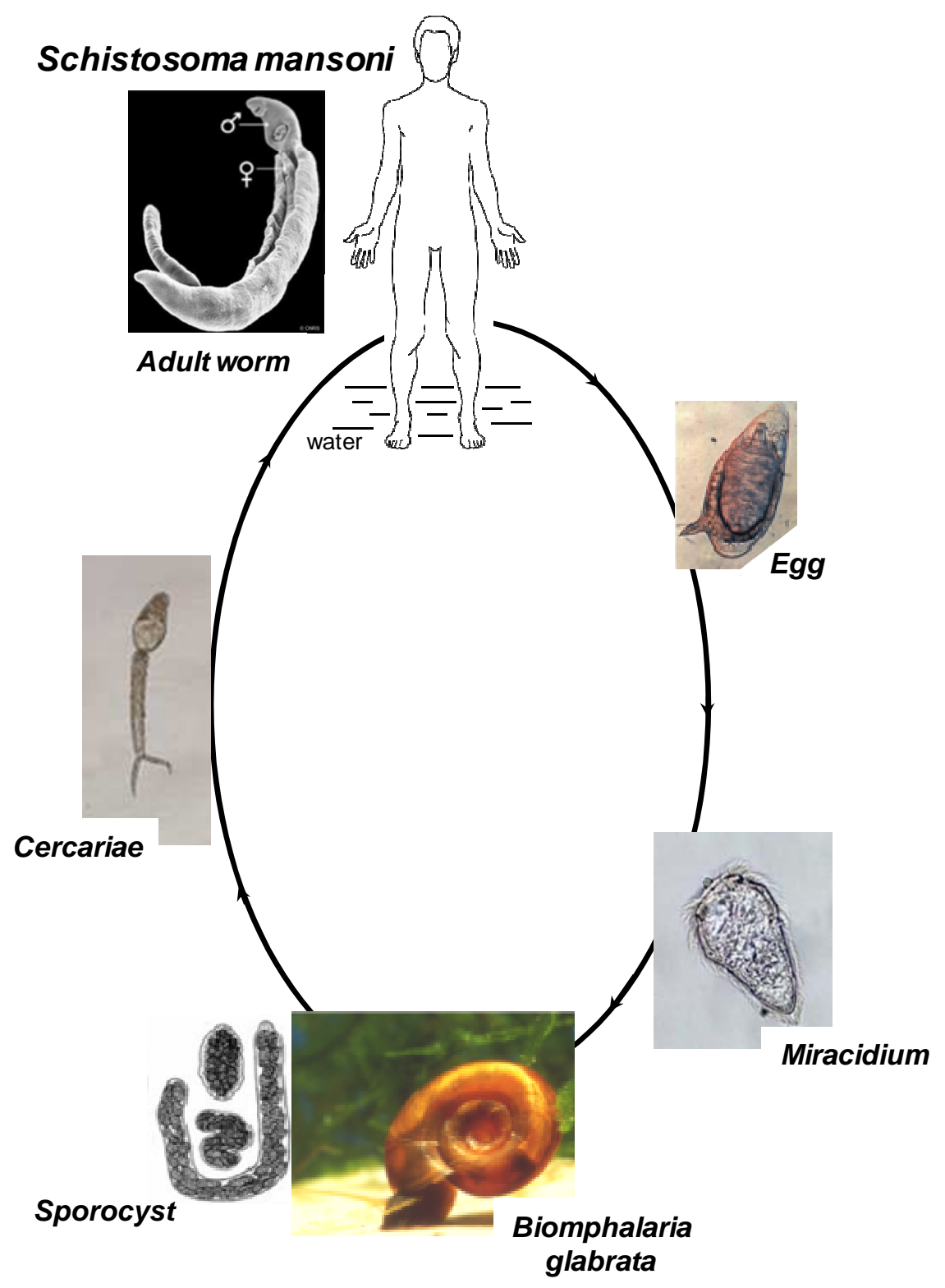


Figure 2

Figure 2

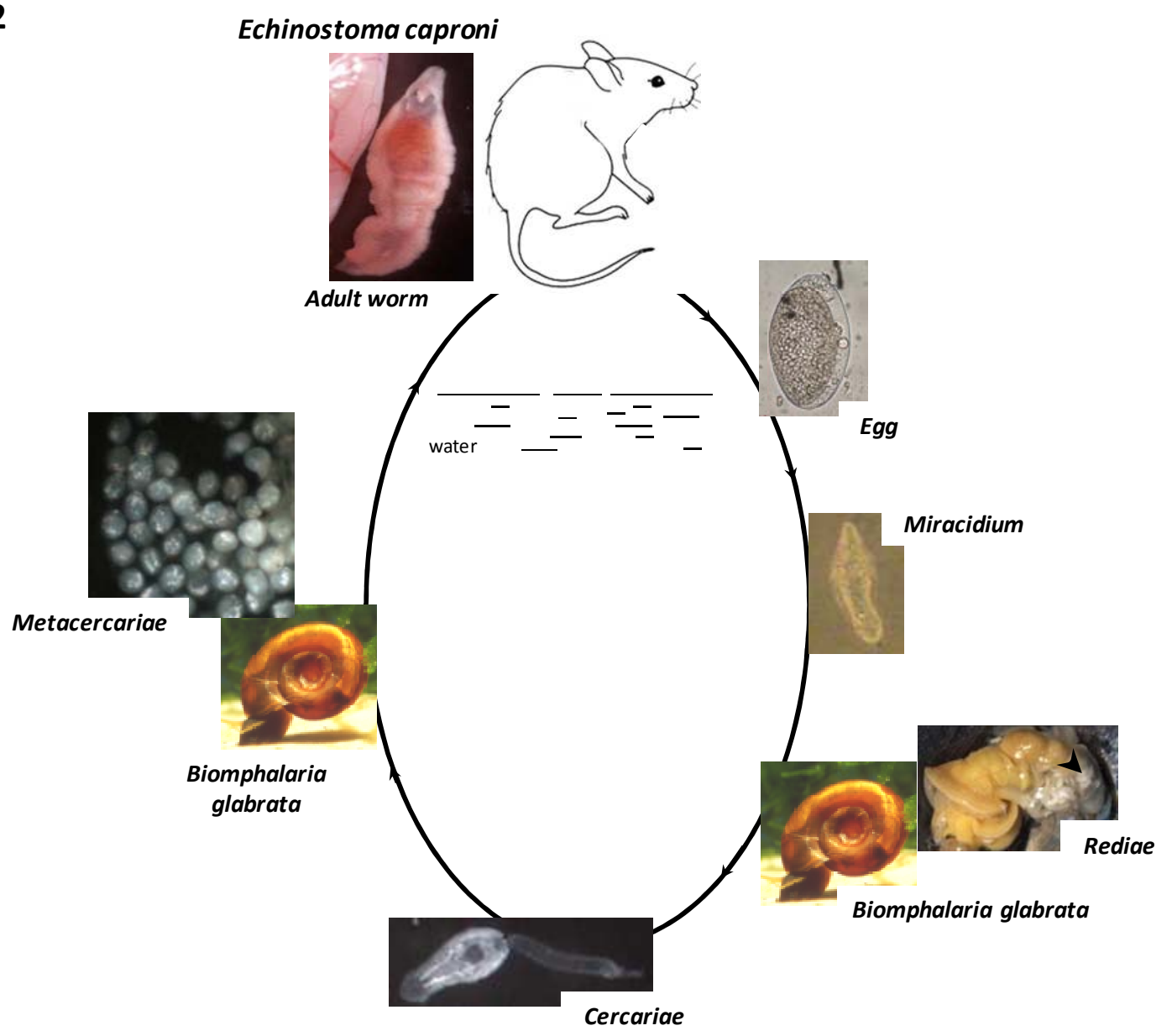


Figure 3

\section{Figure 3}

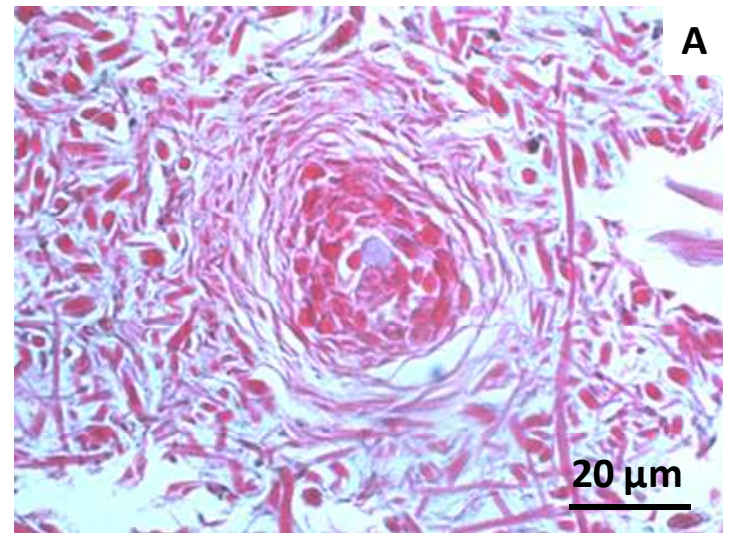

Immediate immune recognition, hemocyte encapsulation and parasite killing.

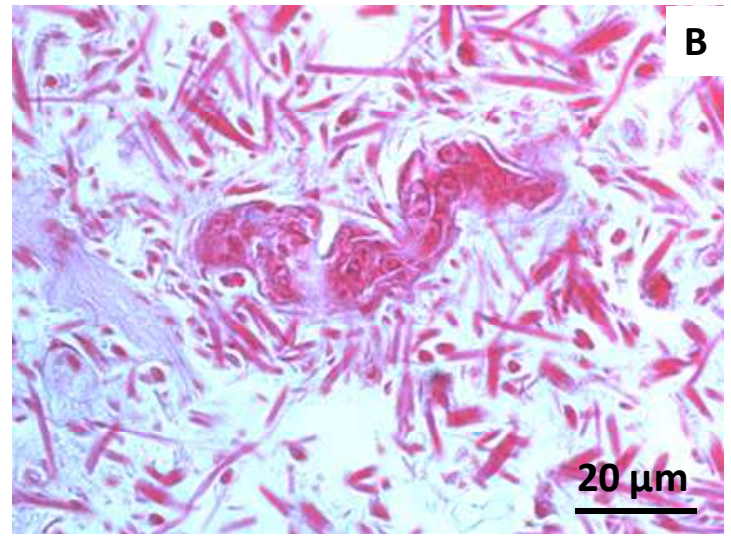

Recognition default and normal parasite development. 